\title{
JAFES: Reducing Obesity and Metabolic Syndrome; Meeting in Ho Chi Minh City, Vietnam for the First Time
}

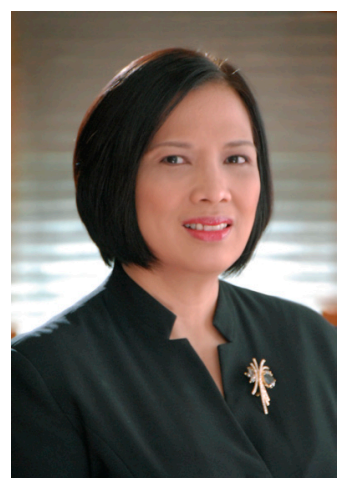

The huge success of the $6^{\text {th }}$ Asia-Oceania Conference on Obesity in Manila, Philippines, on August 31 to September 2, 2011, inspired the editorial team to focus on the epidemic of obesity and the metabolic syndrome in the ASEAN Region.

Firstly, the obesity rates in the region are clearly rising, with the epidemic particularly affecting children who comprise a growing segment of the population. Secondly, existing data provide evidence for the strong link between obesity and its cardio-metabolic consequences, which in fact occur even at lower body mass index (BMI) levels, with increasing visceral adiposity. Thirdly, there is a discussion on strategies for prevention and control that are applicable to the region, using population approaches with impact to communities, both urban and rural, and particularly school-based programs. To remind us of this social responsibility and to formalize a commitment within the region, all member countries of the Asia-Oceania Association for the Study of Obesity (AOASO), signed a joint declaration on September 2, 2011, which we publish in this issue.

Impelled by the need to focus on these conditions, the current issue focuses on clinical practice guidelines (CPGs) for obesity in the region. Many of the countries in ASEAN are in the early stages of working on this health issue; few have established country-specific guidelines. Invited reviews provide perspectives on the etiology of the burden of disease, with specific focus on ASEAN initiatives. Dr. Rodolfo Florentino, talks on the double burden of increasing obesity in one segment of the population along with malnutrition in another population segment, a unique but even greater problem occurring in most countries in South East Asia. Pediatrician-geneticist Dr. Eva Cutiongco-dela Paz, reviews the genes related to obesity and its applications in Asia, as we work for effective and specific treatment strategies. Lastly, Dr. Augusto Litonjua, the founding president of the AFES and the Philippine Association for the Study of Overweight and Obesity (PASOO), reviews trends and obesity patterns in the Philippines, elucidating differential phenotype and potential differential genotype of obesity and the metabolic syndrome in this population.

Insightful original work such as a pilot study on the use of neck circumference as a screening measure for abdominal obesity as a surrogate diagnostic test for visceral obesity is presented here. Previous studies in Israeli patients determined a cut-off and this simple screening measure needs to be validated in various ethnic populations. Traditionally, in many Asian countries, we would check whether a pair of pants would fit by trying its waist part, folded flat, around the neck. The study does not provide clear generalizable relationships yet, but is interesting as a pilot: the authors recommend a prospective study with a bigger sample size.

This issue also includes original articles on insulin resistance from Malaysia, prevalence of obesity, metabolic syndrome and diabetes in selected villages in Indonesia as well as risk factors associated with arterial stiffness in Asians with diabetic nephropathy from Singapore. We likewise have a number of interesting case reports and images from endocrinology cases in our region, which often times are no longer seen as clinical presentation in the Western world.

Meanwhile, excitement is building up as AFES countries meet in Ho Chi Minh City, Vietnam for the first time this November. The theme of the $16^{\text {th }}$ AFES congress is "Translating Endocrinology Research into Clinical Care." A JAFES Supplement accompanies this issue with the highlights of the Congress proceedings, including oral and poster research abstracts. Vietnam Association for Diabetes and Endocrinology (VADE) President Nguyen Van Thue provides an introduction to the scientific and social programs for this important biennial meeting. 
We encourage our colleagues in ASEAN to spread the word: we have JAFES, the journal that serves as our voice in the region and the world. We are now accessible 24 hours a day, 7 days a week on the internet at this address: http://www.asean-endocrinejournal.org. Authors who wish to submit their manuscripts can now do so not only through e-mail (IAFES@Asia.com) but also through the website. Abstracts and selected articles from the previous issue are currently available for download. For the benefit of our authors and readers, efforts on making JAFES Medline-indexed are now underway.

We are committed to focus on themes that have relevance to our individual and collective countries, and hope to provide an impetus for action. We aim to translate country-specific research to public health programs and policies and clinical practice. Please continue to email me your comments at epaz-pacheco@asean-endocrinejournal.org.

\section{Elijabet If lachees \\ Elizabeth Paz-Pacheco \\ Editor-in-Chief}

